\title{
O Instituto de Física e suas principais linhas de pesquisa
}

\section{HENRIQUE FLEMING}

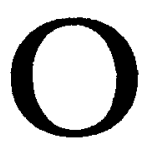

atual Instituto de Física é a continuação do Departamento de Física da Faculdade de Filosofia, Ciências e Letras. Sua fundação, por isso, coincide com a da Universidade. Erigido praticamente ex nibilo pelo gênio de Gleb Wataghin, caracterizou-se, desde o início, como centro de pesquisas de vanguarda na estrutura da matéria. Em sua primeira década já apresentava pesquisas reconhecidas internacionalmente na física experimental dos raios cósmicos e na física teórica. Em 1950 Wataghin publicava trabalho fundamental sobre a nucleossíntese nas estrelas.

Estão aí identificadas as linhas de pesquisa que aqui sempre existiram: a física nuclear e a física das partículas elementares, ambas herdeiras da tradição dos raios cósmicos. Mais tarde deveu-se à visão de Mário Schenberg a criação de um vigoroso grupo de física da matéria condensada. A essas pesquisas se juntaram, pouco a pouco, a física da poluiçáo do ar, o ensino da física e a física do plasma.

Tratando-se de um vasto instituto, com dezessete prédios e cerca de duzentos professores distribuídos em seis departamentos, perde qualquer sentido arrolar todas as linhas de pesquisa em suas especificidades. $O$ que faremos é apontar, por departamento, as áreas da física aqui desenvolvidas.

\section{Linhas de pesquisa}

- Departamento de Física dos Materiais e Mecânica:

magnetismo;

ultra baixas temperaturas;

materiais magnéticos;

espectroscopia Mössbauer;

estrutura eletrônica;

semicondutores;

supercondutividade.

- Departamento de Física Matemática:

teoria quântica de campos e física das partículas elementares; 
teoria dos muitos corpos para sistemas nucleares;

física matemática.

- Departamento de Física Experimental:

ótica de cristais líquidos;

ensino da física;

emulsóes nucleares;

espectroscopia nuclear;

eletrodesintegração nuclear;

reaçóes fotonucleares e fissão;

altas energias e raios cósmicos;

física nuclear teórica e fenomenologia das partículas elementares.

- Departamento de Física Nuclear:

física nuclear experimental (pelletron);

desenvolvimento de aceleradores;

desenvolvimento de fontes de íons;

física nuclear teórica;

computaçáo e sistemas digitais;

física aplicada à medicina, à arqueologia e proteçăo radiológica;

ultra alto vácuo;

técnicas nucleares na engenharia dos materiais;

física experimental de partículas elementares;

ondas gravitacionais e antenas.

- Departamento de Física Aplicada:

cristalografia;

instrumentos para o ensino;

poluição do ar;

física de plasmas;

ressonância magnética;

concepçóes alternativas em física;

colisões iônicas.

- Departamento de Física Geral:

instrumentação e partículas ( Lons pesados e leves, estrutura e reaçóes nucleares);

microscopia eletrônica;

magneto-ótica;

biofísica e física médica;

metrologia ótica e holografia interferométrica;

ressonância magnética; 
física estatística (modelos de spins, fenômenos multicríticos, transiçóes de fases, redes neurais etc.);

física teórica (turbulência, caos, microondas, ondas gravitacionais).

\section{Comentários e referências}

Uma linha de pesquisa só é citada quando produziu publicaçóes em revistas especializadas internacionais.

Mais informaçóes poderão ser obtidas junto aos Departamentos citados ou à Comissão de Pesquisa do Instituto.

A Biblioteca do Instituto de Física da USP é a maior da área no Brasil, e está aparelhada para atender usuários de outras instituiçóes pelo sistema Comut.

Boas referências para maiores detalhes são os Relatórios Anuais dos Departamentos e o Relatório Geral do Instituto, bem como o Manual de Pós-Graduafño, que podem ser obtidos nas secretarias dos departamentos, na diretoria do Instituto e na Secretaria de Pós-Graduação, respectivamente.

Henrique Fleming é professor do Departamento de Física Matemática do Instituto de Física da USP. 